\title{
Direct-to-consumer advertising of prescription medicines: a counter argument
}

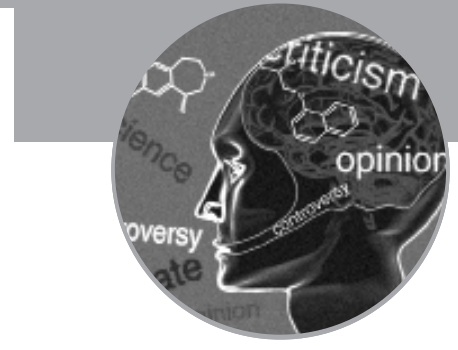

Direct-to-consumer advertising of prescription-only medicines is currently only permitted in the USA and New Zealand. Barbara Mintzes and Dee Mangin provide their case against direct-to-consumer advertising of prescription medicines, arguing that its wider introduction would lead to a 'Pharma-knows-best' culture.

Should direct-to-consumer advertising (DTCA) of prescription drugs be allowed in jurisdictions where it is currently banned? In his article 'The case for advertising pharmaceuticals direct to consumers', published in Future Medicinal Chemistry, Frank Auton argues that DTCA leads to improved diagnosis and treatment, better doctor-patient relationships, a more educated and informed public and that DTCA represents an inevitable wave of the future in an era in which paternalistic 'doctor-knows-best' attitudes are no longer relevant [1].

These arguments are timely. The EU is once again considering proposed reforms to pharmaceutical legislation, including a highly controversial 'patient information' initiative involving some forms of DTCA [2]. Recently, Canada's largest media company, CanWest, mounted a charter-of-rights challenge of the ban on DTCA, arguing that the law infringed its freedom of expression. The case was adjourned 'at the 11th hour' in June 2009, due to financial insolvency [3].

\section{"There is no public health rationale for the introduction of DTCA, no reliable evidence that \\ it leads to better care, public or patient \\ empowerment or to the type of information needed for shared informed treatment choices."}

The rationale for the prohibition of DTCA is health protection. Medicines have prescriptiononly status because they are more toxic than over-the-counter drugs. They often treat more serious conditions, for which both diagnosis and treatment are complex, and require a physician's assistance. In an aging population, multiple comorbid conditions are the norm and there is great potential for drug-drug and drug-disease interactions. People with serious diseases are vulnerable to messages of hope in misleading advertising in a way that someone buying a new pair of jeans is not. Individuals have limited means to evaluate the scientific evidence underpinning advertising claims for medicines. The choice of a medicine should be based on the greatest benefit to overall quality of life rather than the most powerful advertising message.

“...many of the claimed benefits for DTCA do not stand up to scrutiny and evidence on harm is largely omitted."

There is no public health rationale for the introduction of DTCA, no reliable evidence that it leads to better care, public or patient empowerment or to the type of information needed for shared informed treatment choices. DTCA does lead to more frequent medicine use and to substitution of expensive new brands for equally effective, less-costly alternatives [4]. It has led to the use of unnecessarily harmful medicines and can expand the market for drug classes to those unlikely to benefit and encourage treatment of milder health problems for which nondrug solutions are often more appropriate. All medicine use is a balancing act, weighing up potential benefits and harms. As the problem treated becomes milder, benefit shrinks and the potential for harm can outweigh benefit.

Auton presents a highly selected subset of the research evidence on DTCA, much of it produced by, or on behalf of, pharmaceutical manufacturers. As is discussed below, many of the claimed benefits for DTCA do not stand up to scrutiny and evidence on harm is largely omitted.

We agree with Auton that the quality of medicine use could be improved and that the public can benefit from better access to health and treatment information, but we would suggest different means, including a ban on DTCA as one important aspect. Information can influence healthcare choices in different ways. An individual may come to a decision based on an assessment of the available evidence presented neutrally. This is the basis of shared informed

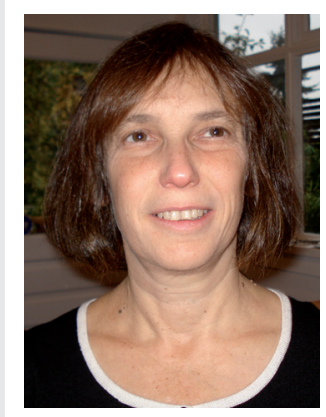

Barbara Mintzes

Author for correspondence

Therapeutics Initiative,

University of British

Columbia, 2176 Health

Services Mall, Vancouver

BC, V6T IZ3, Canada

Tel.: + I 6048227130

Fax: + I 604822 070।

E-mail: barbara.mintzes@

ti.ubc.ca

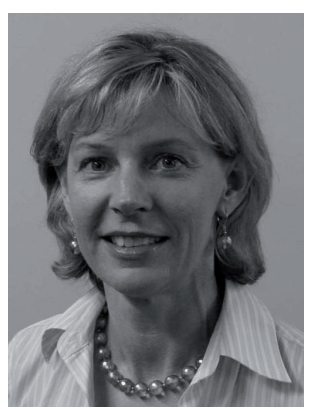

Dee Mangin

Director Primary Care

Research, Christchurch

School of Medicine, University

of Otago, New Zealand

Tel.: + 6433643636

Fax: + 6433643637

E-mail: dee.mangin@

otago.ac.nz

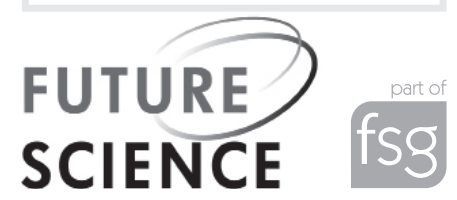


decision making and is fundamental to respect for autonomy. By contrast, information manipulation is a deliberate act of managing information that alters a person's understanding of a situation in order to motivate him or her to do what the agent of influence intends. This is precisely how advertising acts: by definition, it seeks to drive decisions in favor of the advertised medicine. This is not shared informed decision making or consumer empowerment. In an era that values respect for autonomy, DTCA is unsustainable.

Improving provision and access to independent information for consumers and physicians would help make shared informed treatment choices more of a reality [101] and likely be costeffective, as would better regulation of drug promotions targeting physicians. Recent US court cases have uncovered a range of promotional practices of grave concern, such as widespread promotion for unapproved uses without evidence of effectiveness, use of physician 'key opinion leaders', sponsored continuing medical education to promote sales [5] and ghostwriting of scientific articles $[6,102]$.

\section{DTCA \& harm: the case of rofecoxib $\left(\right.$ Vioxx $\left.^{\circledR}\right)$}

In September 2004, Merck executive Pier Wold Olsen argued that the introduction of DTCA in Europe would save lives: "Patient Information Deprivation Syndrome" he claimed, was "of epidemic proportions" causing many Europeans "to suffer or die needlessly" [7]. Olsen's remarks were published less than a month before the global withdrawal of Merck's arthritis drug rofecoxib $\left(\right.$ Vioxx $\left.^{\circledR}\right)$. From 1999 to 2004, rofecoxib was among the most heavily advertised medicines in the USA [8] and New Zealand [9]. Rofecoxib is no more effective than other anti-inflammatory drugs. Cardiologist Eric Topol described Merck's DTCA spending of over US $\$ 100$ million per year as a "critical mechanism in building the "blockbuster' status of a drug with annual sales of more than US $\$ 1$ billion" [8].

In March 2008, Merck agreed to a settlement of US $\$ 58$ million with 29 US states that alleged the company had downplayed the product's risks in advertising. Tom Corbett, Attorney General for Pennsylvania, stated that Merck had run "an aggressive and deceptive advertising campaign, which misrepresented the safety and improperly concealed the increased risks associated with Vioxx" [103]. Combined epidemiological and clinical trial evidence yielded an estimate of 88,000-140,000 heart attacks caused by rofecoxib exposure in the USA, $44 \%$ of which would have been fatal [10]. A second study estimated that rofecoxib caused 16 heart attacks per 1000 users [8].

What was the contribution from DTCA? At a mean of US $\$ 3.66$ in returns per advertising dollar invested for blockbuster drugs [104], around 39\% of the US $\$ 1.518$ billion in sales in 2000 would have been stimulated by the US $\$ 160.8$ million spent on DTCA [105]. In a study that combined medical records and survey results among patients insured by Kaiser Permanente, Spence et al. found that $20 \%$ of rofecoxib and celecoxib users had requested prescriptions after seeing DTCA. These prescriptions were four-times as likely as others to be inconsistent with treatment guidelines [11]. A further study found that both consultations and prescribing increased with increasing DTCA spending [12].

\section{"Advertisements often use images of healthy women to sell statins, casting a wider net than those likely to benefit in order to stimulate sales..."}

Other medicines advertised to the US public have been withdrawn for safety reasons, including benoxaprofen $\left(\mathrm{Oraflex}^{\circledR}\right)$ for arthritis, troglitazone $\left(\right.$ Rezulin $\left.^{\circledR}\right)$ for diabetes, cisapride (Propulsid $^{\circledR}$ ) for gastric reflux, cerivastatin $\left(\right.$ Baycol $\left.^{\circledR}\right)$ to lower cholesterol [13] and tegaserod $\left(\right.$ Zelnorm $\left.^{\circledR}\right)$ for irritable bowel syndrome in women [14]. Tegaserod was withdrawn in 2007. The first US safety advisory was in 2004 . A television commercial that was widely broadcast in 2006 included eye-catching images of women baring their stomachs, revealing advertising slogans. Effectiveness was compared with fiber and laxatives, implying use for mild problems, and shots panning a large group of women of many ages and races implied widespread use [15].

Is the public aware that advertised medicines may have serious risks? A national US FDA survey found that $29 \%$ of consumers believed that only completely safe medicines could be advertised on television [106]; in California, $42 \%$ believed that only the safest drugs could be advertised [16]. No such safeguards exist.

\section{Does DTCA help the undertreated obtain needed care?}

Auton discusses undertreatment of a number of conditions in US settings and recommends DTCA as a solution. The most pressing change needed to address undertreatment in the USA is full population insurance coverage and access 
to healthcare, regardless of ability to pay or preexisting health conditions. Such reforms have little or nothing to do with DTCA, except insofar as DTCA provides a barrier by driving up healthcare costs.

The example of statins for primary prevention as an area of undertreatment to be remedied by DTCA bears closer examination. Women are often prescribed statins and are among those counted as undertreated, despite the lack of evidence of a reduction in serious morbidity or mortality. Use of statins places women at risk for adverse effects, such as muscle damage and cognitive impairment, for no benefit. Similarly, there is no benefit to statin use in primary prevention in older people [17]. On the other hand, statins have clear health benefits for middle-aged men with previous heart disease, who are at high risk of heart attack. Advertising communicates the idea that high cholesterol is a health problem. In reality, it is simply a physiological measure. The only rationale for statin use is prevention of cardiovascular disease. Cholesterol levels alone are a poor predictor of individual risk; they are helpful when judged along with other factors, such as smoking, family history and high blood pressure, and then only in certain sections of the population. Despite this, advertisements often use images of healthy women to sell statins, casting a wider net than those likely to benefit in order to stimulate sales.

Caution is also needed in interpreting epidemiological surveys of disease prevalence to imply that widespread drug treatment is needed. Auton cites "overwhelming evidence" of undertreatment of depression when safe, effective and economic treatments exist. In the largest US epidemiological survey, treatment rates were lowest among those with the mildest depression and highest among those with more severe problems [18]. A total of $20 \%$ of those identified as having depression reported no impairment at work and $13 \%$ reported no or mild impairment in all domains. A Canadian epidemiological survey found that a fourth of episodes of depression among those without treatment were resolved in 3 weeks, half within 5 weeks [19]. The National Institute of Clinical Excellence (NICE) advises against antidepressant treatment of mild depression because the risk-benefit ratio is poor and most people recover with lifestyle measures. The evidence for effectiveness of antidepressants is small: only around $15 \%$ of the response effect is due to the drug and the majority of the effect is placebo response [20]. Selective publication of clinical trials has contributed to overestimation of effectiveness [21].
The FDA has judged a number of antidepressant adverts to be illegal due to the widening of diagnostic boundaries. For example, a radio advert for venlafaxine (Effexor ${ }^{\circledR}$ or Efexor $\left.{ }^{\circledR}\right)$ "fails to communicate important characteristics necessary to distinguish between major depressive disorder and variations of normal daily functioning" [107]. If people see such advertisements and request a prescription when they do not have depression, they are highly likely to receive it. A randomized controlled trial using standardized patients found that patient requests for an advertised antidepressant were a stronger predictor of prescribing decisions than whether or not the patient actually had depression, the condition antidepressants have been approved to treat. In this study, patient requests led to more prescriptions both for depression and for milder 'adjustment disorder' due to life problems, but the effect was much stronger on the latter [22].

\section{"The FDA has judged a number of antidepressant adverts to be illegal due to the widening of diagnostic boundaries."}

Auton cites a study by Weissman and colleagues, funded by a consortium of drug companies, to support a claim that DTCA leads to more diagnoses of high-priority conditions [23]. This study had no control group; the methods used did not allow them to know whether there were fewer or more such diagnoses in these consultations than in consultations unaffected by DTCA. An accompanying commentary characterized the study as one of two "advertisements for TV drug advertisements" [24].

\section{Does DTCA improve compliance?}

There is no reliable evidence that DTCA improves compliance. Auton cites several physician opinion surveys in which some physicians agreed with statements that DTCA improved compliance and others did not. Such opinion surveys cannot accurately measure compliance. Auton also cites data from an unpublished Pfizer study that is not publicly available. Another study, by Donohue and colleagues, is cited to show that, at times of greater DTCA exposure, patients were more likely to stay on treatment for at least as long as is recommended in treatment guidelines [25]. This study unsurprisingly found that DTCA led to more antidepressant prescriptions. Their appropriateness is unknown and brand-specific spending failed to affect treatment duration. Competitor 


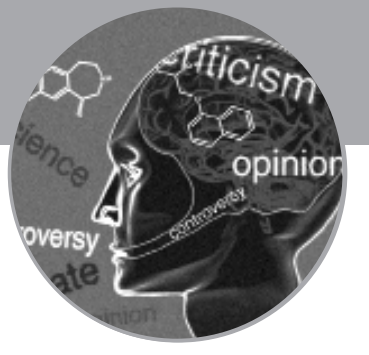

spending had a small effect on other brands at the highest spending levels. This intuitively implausible result may be an artefact of the authors' failure to adjust their analysis for multiple comparisons. The authors state: "We found no evidence ... that pharmaceutical promotion to consumers or physicians has an important impact on the likelihood that therapy would be continued in a way that meets existing guidelines".

\section{How well does DTCA communicate health \& drug information?}

Numerous studies have shown that the information communicated in DTCA is of limited to no educational value. Researchers examined over 320 magazine adverts published over a 10 -year period. The large majority failed to mention the likelihood of treatment success, other available options, causes or risk factors for the condition or how the drug works [26]. Another analysis found that nearly nine out of ten magazine adverts describe benefits in vague terms and failed to provide evidence to support claims [27]. Free trial offers were common. Television advertising uses emotive messages linking medicine use with control over one's life, happiness and social approval [28]. US regulatory violations are frequent and most involve minimization of risk information or exaggeration of benefits [108]. The FDA is only able to review a small proportion of DTCA and, on average, advertising runs for 5 additional months after the FDA has first judged it to be illegal [109].

\section{"A drug company cannot be expected to inform the public that its competitor's product represents a treatment advantage over its own..."}

\section{Are new medicines better or just costlier?}

The focus of DTCA campaigns is overwhelmingly on new, on-patent medicines [29]. Very few of these represent a therapeutic advance and most are more expensive. To obtain market approval for a new medicine, a manufacturer does not need to show that it is better than existing alternatives. A drug can be licensed simply by demonstrating treatment effect on some measure versus placebo. Many harmful effects remain unknown, especially longerterm and infrequent effects. Most DTCA spending occurs in the first 2 years of marketing [29], which is also when most drug safety withdrawals occur [30].
The French independent bulletin La Revue Prescrire evaluates all new drugs and indications approved in France for subscribing physicians and pharmacists. From 1999 to 2008, of 961 evaluated, $2 \%$ were clear treatment advances and another $9 \%$ had some advantages. A further $23 \%$ were possibly helpful, $49 \%$ nothing new, $11 \%$ riskier or less effective than existing treatments and, for $6 \%$, clinical evidence was too limited to allow evaluation [31]. These evaluations were based on systematic reviews of the full available clinical trial evidence, including both published and unpublished reports. In most cases, existing scientific evidence failed to support a likely health benefit from the rapid expansion of the use of newer therapies.

\section{Conclusion}

A drug company cannot be expected to inform the public that its competitor's product represents a treatment advantage over its own, that a cheaper but equivalent alternative exists or that normal sadness in response to a life crisis should not be treated with a medicine. Manufacturers have a fiduciary responsibility to their shareholders to maximize product sales. There is no doubt that DTCA influences patient demand for advertised medicines and physician prescribing behaviors [4]. Auton states that the information age has meant the end to paternalistic 'doctor knows best'. DTCA simply allows this to be replaced with 'Pharma knows best'.

\section{Financial \& competing interests disclosure}

Barbara Mintzes holds a Michael Smith Health Research Foundation Scholar Award. She was a consultant to the Canadian Department of Justice during the legal case in which CanWest media challenged the ban on directto-consumer advertising. Dee Mangin is an expert witness for the plaintiff in cases involving Paxil and birth defects. She is a member of and was previously on the management committee of Healthy Skepticism. She has been an invited speaker on aspects of rational prescribing at conferences, some of which were sponsored by pharmaceutical companies. The authors have no other relevant affiliations or financial involvement with any organization or entity with a financial interest in or financial conflict with the subject matter or materials discussed in the manuscript. This includes employment, consultancies, honoraria, stock ownership or options, expert testimony, grants or patents received or pending, or royalties.

No writing assistance was utilized in the production of this manuscript. 


\section{Bibliography}

1 Auton F. The case for advertising pharmaceuticals direct to consumers. Future Med. Chem. 1(4), 587-592 (2009).

2 Richards T. Purely medicinal? BMJ 336, 693 (2008).

3 Silversides A. Charter challenge of ban on direct-to-consumer advertising to be heard by Ontario court in mid-June. CMAJ 181, E5-E6 (2009).

4 Gilbody S, Wilson P, Watt I. Benefits and harms of direct to consumer advertising: a systematic review. Qual. Safety Health Care 14, 246-250 (2005).

5 Steinman MA, Bero LA, Chren MM, Landfeld CS. Narrative review: the promotion of gabapentin: an analysis of internal industry documents. Ann. Intern. Med. 145, 284-293 (2006).

6 Gotzsche PC, Hrobjartsson A, Johansen HK et al. Ghost authorship in industryinitiated randomised trials. PLoS Med. 4(1), 47-51 (2007).

7 Merck \& Co invents new syndrome information deprivation. Scrip. Bulletin 2983, 5 (2004).

8 Topol EJ. Failing the public health rofecoxib, Merck and the FDA. N. Engl. J. Med. 351, 1707-1709 (2004).

9 Norris P, Nelson L, Ling KL et al. Advertising of medicines on New Zealand television. NZ Med J. 118, 1462 (2005).

10 Graham DJ, Campen D, Hui R, Spence $\mathrm{M}$ et al. Risk of acute myocardial infarction and sudden cardiac death in patients treated with cyclo-oxygenase 2 selective and non-selective non-steroidal antiinflammatory drugs: Nested case-control study. Lancet 365 (9458), 475-481 (2005).

11 Spence M. Teleki SS, Cheetham TC, Schweitzer SO, Millares M. Direct-toconsumer advertising of COX-2 inhibitors: effect on appropriateness of prescribing. Med. Care Res. Rev. 62, 544-549 (2005).

12 Bradford WD, Kleit AN, Nietert PJ et al. How direct-to-consumervtelevision advertising for osteoarthritis drugs affects physicians' prescribing behavior. Health Aff. 25, 1371-1377 (2006).

13 Lexchin J, Mintzes B. Direct-to-consumer advertising of prescription drugs: the evidence says no. J. Public Policy Market. 21(2), 194-201 (2002).

14 Law MR, Majumdar SR, Soumerai SB. Effect of illicit direct to consumer advertising on use of etanercept, mometasone, and tegaserod in Canada: controlled longitudinal study. BMJ 337 , A1055 (2008).
15 Mintzes B. Direct to consumer advertising of prescription drugs. Even attenuated forms such as cross border advertising can cause harm. BMJ 337, A985-A985 (2008).

16 Bell RA, Wilkes MS, Kravitz RL. Advertisement-induced prescription drug requests; patients' anticipated reactions to a physician who refuses. J. Fam. Pract. 48(6), 446-552 (1999).

17 Mangin D, Sweeney K, Heath I. Preventive health care in elderly people needs rethinking. BMJ 335, 285-287 (2007).

18 Kessler RC, Berglund P, Demler O et al. The epidemiology of major depressive disorder: results from the national comorbidity survey replication (NCS-R). JAMA 289, 3095-3105 (2003).

19 Patten SB. The impact of antidepressant treatment on population health: synthesis of data from two national data sources in Canada. Popul. Health Metr. 2(1), 9 (2004).

20 Arroll B, Macgillivray S, Ogston S, Reid I et al. Efficacy and tolerability of tricyclic antidepressants and SSRIs compared with placebo for treatment of depression in primary care. A meta-analysis. Ann. Fam. Med. 3(5), 449-456 (2005).

21 Turner EH, Matthews AM, Linardatos E et al. Selective publication of antidepressant trials and its influence on apparent efficacy. N. Engl. J. Med. 358, 252-260 (2008).

22 Kravitz RL, Epstein RM, Feldman MD et al. Influence of patients' requests for direct-to consumer advertised antidepressants: a randomised controlled trial. JAMA 293, 1995-2002 (2005).

23 Weissman JS, Blumenthal D, Silk AJ et al. Consumers' reports on the health effects of direct-to-consumer drug advertising. Health Aff. 26, W3-W82 (2003).

24 Bodenheimer T. Two advertisements for TV drug ads. Health Affairs 26(W3), 112-115 (2003).

25 Donohue JM, Berndt ER, Rosenthal M, Epstein AM, Frank RG. Effects of pharmaceutical promotion on adherence to the treatment guidelines for depression. Med. Care. 42, 1176-1185 (2004).

26 Bell RA, Wilkes MS, Kravitz RL. The educational value of consumer-targeted prescription drug print advertising. J. Fam. Pract. 49(12), 1092-1098 (2000).

27 Woloshin S, Schwartz LM, Tremmel J, Welch HG. Direct-to-consumer advertisements for prescription drugs: What are Americans being sold? Lancet 358, 1141-1146 (2001).

28 Frosch DL, Krueger PM, Hornik RC, Cronholm PF, Barg FK. Creating demand

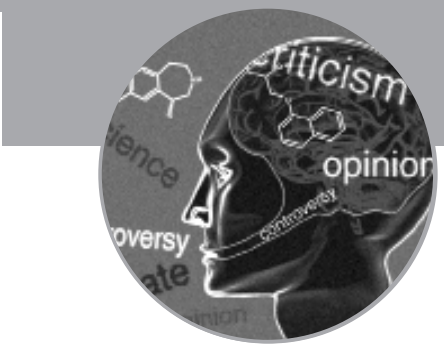

for prescription drugs: a content analysis of television direct-to-consumer-advertising. Ann. Fam. Med. 5(1), 6-13 (2007).

29 Donohue JM, Cevasco M, Rosenthal MB. A decade of direct-to-consumer advertising of prescription drugs. N. Engl. J. Med. 357, 673-681 (2007).

30 Lasser KE, Allen PD, Woolhandler SJ, Himmelstein DU, Wolfe SM, Bor DH. Timing of new black box warnings and withdrawals for prescription medications. JAMA 287, 2215-2220 (2002).

31 La Revue Prescrire. A look back at 2008: pharmaceutical quality problems. Prescrire Internat. 18 (100), 83-88 (2009).

\section{- Websites}

101 Health Action International (HAI-Europe), International Society of Independent Drug Bulletins (ISDB), Association Internationale des Mutualités (AIM), The European Consumers' Organisation (BEUC), Medicines in Europe Forum (MEiF): Relevant Health Information for Empowered Citizens. Joint Declaration. 3 October, 2006 www.haiweb.org/01102006/ patientinformationdeclaration.pdf

102 Saul S. Ghostwriters used in Vioxx studies, article says. New York Times 15 April, 2008 www.nytimes.com/2008/04/15/ business/15cnd-vioxx.html

103 Attorney General Corbett announces a multi-state, \$58 million settlement with Merck over deceptive advertising concerning the safety of Vioxx. Pennsylvania Attorney General's Office. Harrisburg, PA, USA, 20 May, 2008 www.attorneygeneral.gov/press.aspx $? \mathrm{id}=3660$

104 Gascoigne D. DTC at the crossroads: a "direct" hit ... or miss? IMS Issues and Insights. Plymouth Meeting, PA, USA, IMS Health, 23 September 2004 www.imshealth.net/vgn/images/portal/ cit_400873/15/35/58020533DTCBrochure 092204.pdf

105 Findlay S. Prescription Drugs and Mass Media Advertising 2000. (2001) Washington DC, National Institute of Health Care Management www.nihcm.org/publications/ prescription_drugs

106 Aikin KJ, Swasy JL, Braman AC. Patient and physician attitudes and behaviors associated with DTC promotion of prescription drugs 


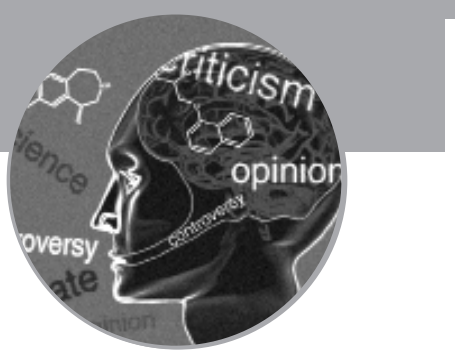

- summary of FDA survey research results. US Dept of Health and Human Services, Food and Drug Administration. Center for Drug Evaluation and Research, 19 November 2004 www.fda.gov/cder/ddmac/final\%20report/ frfinal111904.pdf
107 Williams R. Division of drug marketing, advertising and communication. US FDA. Letter to Tracy Rockney, Wyeth-Ayerst Laboratories. Rockville MD, USA, 18 March 2004

www.fda.gov/downloads/drugs/ guidancecomplianceregulatoryinformation/ enforcementactivitiesbyfda/

ofviolationletterstopharmaceuticalcompanies/ ucm055353.pdf

108 US General Accounting Office. Report to Congressional Requesters: FDA Oversight of
Direct-to-Consumer Advertising has Limitations. Publication GAO-03-177 (2002) www.gao.gov/new.items/d03177.pdf

109 Crosse M. US General Accounting Office. Prescription drugs: trends in FDA's oversight of direct-to-consumer advertising. Testimony before the Subcommittee on oversight and investigations, Committee on Energy and Resources, House of Representatives. GAO-08-758T, 8 May 2008 www.gao.gov/new.items/d0754.pdf 